\section{Physiological, Morphological, and Energy-use Efficiency Comparisons of LED and HPS Supplemental Lighting for Cucumber Transplant Production}

\author{
Ricardo Hernández ${ }^{\mathbf{1}}$ and Chieri Kubota \\ School of Plant Sciences, the University of Arizona, 1140 E. South Campus \\ Drive, Tucson, AZ 85721-0036
}

Additional index words. daily light integral, light emitting diodes, Cucumis sativus, seedlings, blue:red photon flux ratio, high-pressure sodium, fixture growing efficiency

\begin{abstract}
To increase the available photosynthetic photon flux (PPF) for plant growth, greenhouse growers sometimes use electric lighting to supplement solar light. The conventional lighting technology used to increase $P P F$ in the greenhouse is high-pressure sodium lamps (HPS). A potential alternative to HPS is high-intensity light-emitting diodes (LEDs). The objective of this study is to compare supplemental LED lighting with supplemental HPS lighting in terms of plant growth and morphology as well as discuss the energy use efficiencies of the fixtures. There were three light treatments: 1) blue LED (peak wavelength $443 \mathrm{~nm}$ ); 2) red LED (peak wavelength $633 \mathrm{~nm}$ ); and 3) HPS, to provide $3.7 \pm 0.2 \mathrm{~mol} \cdot \mathrm{m}^{-2} \cdot \mathrm{d}^{-1}$ (background solar radiation of $6.3 \pm 0.9 \mathrm{~mol} \cdot \mathrm{m}^{-2} \cdot \mathrm{d}^{-1}$ ). Cucumber (Cucumis sativus) plants at the transplanting stage (26 to 37 days) under HPS had $28 \%$ greater dry mass than did plants under the LED treatments. This can be attributed to the higher leaf temperature under the HPS treatment. No differences were observed in growth parameters (dry mass, fresh weight, or number of leaves) between the blue and red LED treatments. Plants under the blue LED treatment had greater net photosynthetic rate and stomatal conductance $\left(g_{S}\right)$ than those under the red LED and HPS treatments. Plants under the blue LED and HPS treatments had $46 \%$ and $61 \%$ greater hypocotyl length than those under the red LED, respectively. The fixture $P P F$ efficiencies used in the experiment were 1.9, 1.7, and $1.64 \mu \mathrm{mol} \cdot \mathrm{J}^{-1}$ for the blue LED, red LED, and HPS treatments, respectively; however, the fixture growing efficiency $\left(\mathrm{g} \cdot \mathrm{kWh}^{-1}\right)$ of HPS was $6 \%$ and $17 \%$ greater than the blue LED and red LED treatment, respectively. In summary, supplemental red LED produced desirable plant compactness and HPS had greater fixture growing efficiency than LEDs.
\end{abstract}

Light is one of the limiting factors for plant growth. To increase the $P P F$ for plant growth, greenhouse growers must supplement solar light with electric-powered light. The most common lighting technology used to increase $P P F$ in the greenhouse is HPS. HPS are well accepted as a result of their relatively high fixture $P P F$ efficiency. For example, single-ended and double-ended magnetic and electronic HPS PPF efficiencies range between 0.93 to $1.85 \mu \mathrm{mol} \cdot \mathrm{J}^{-1}$ (Nelson and Bugbee, 2013, 2014; Philips-Electronics, 2012). An alternative to HPS is the high-intensity LEDs, which currently have reportedly a $P P F$ efficiency ranging between 0.84 and $2.3 \mu \mathrm{mol} \cdot \mathrm{J}^{-1}$ (Nelson and Bugbee, 2013, 2014; Philips, 2014) and are projected to have a 20 -fold

Received for publication 2 Oct. 2014. Accepted for publication 11 Dec. 2014

This project was funded by USDA NIFA SCRI grant No. 2010-51181-21369.

We thank Mark Kroggel and Neal Barto at the University of Arizona (CEAC) for their technical advice and Jose Pablo Santana for his help during the experiment.

${ }^{1}$ To whom reprint requests should be addressed; e-mail ricahdez@email.arizona.edu. increase on their flux per lamp output over the next decade (Haitz and Tsao, 2011).

In addition to their higher efficiencies, LED fixtures can also be built with a customized spectrum. By using different color diodes, growers have the opportunity to optimize spectra for specific growing purposes. In research using LEDs as the sole source light, plants such as peppers, wheat, lettuce, potato plantlets, Arabidopsis thaliana, soybeans, spinach, and radish grown under red light $(600$ to $700 \mathrm{~nm})$ supplemented with blue light (400 to $500 \mathrm{~nm}$ ) had greater growth rate and better plant development than plants grown under red light alone (Brown et al., 1995; Goins et al., 1997; Kim et al., 2005; Massa et al., 2008). Among limited information, recent studies testing LEDs as supplemental lighting have shown that the optimal electrical light spectrum for plant growth is different under sole-source lighting than for supplemental lighting For example, Hernández and Kubota (2014a, $2014 \mathrm{~b}$ ) found that plant responses to red and blue photon flux (PF) ratios of LED supplemental lighting were species-specific and dependent on background solar daily light integral (DLI). They concluded that monochromatic red supplemental lighting was preferred for the production of vegetable transplants because cucumber growth rate decreased with the increased of blue PF under low solar DLI $\left(5.2 \pm 1.2 \mathrm{~mol} \cdot \mathrm{m}^{-2} \cdot \mathrm{d}^{-1}\right)$ (Hernández and Kubota, 2014a).

To advance the use of LEDs as a supplemental lighting technology in greenhouses, they have to be compared with the current HPS technology in terms of plant responses and energy consumption. Limited information is available comparing HPS supplemental lighting with LED supplemental lighting in terms of plant growth and development. Currey and Lopez (2013) showed greater leaf and root dry mass on Petunia cuttings grown under LED supplemental lighting with 70:30 red:blue $P F$ ratios compared with the cuttings grown under HPS supplemental lighting. Bergstrand and Schussler (2013) showed that Chrysanthemum plant biomass production was greater under HPS supplemental lighting than those under supplemental red:blue and white LED supplemental lighting. Limited and conflicting research reports are available comparing energy consumption between LED and HPS supplemental lighting. For example, for fresh head lettuce, Martineau et al. (2012) showed greater lettuce dry mass per electric energy input in plants grown under LED supplemental lighting than those under supplemental HPS lighting and reported a $33.8 \%$ greater electricity consumption by the HPS supplemental lighting. In tomato, Gomez et al. (2013) showed no increase in yield under supplemental LED lighting compared with the yield under supplemental HPS lighting, but reported $76 \%$ greater electrical consumption by the HPS supplemental lighting treatment compared with the LED supplemental lighting treatment. Pinho et al. (2012) reported that a small-scale experiment of supplemental lighting (1- $\mathrm{m}^{2}$ plant growing area) consumed a $40 \%$ greater electricity by the HPS lighting than the LED lighting to achieve the same $P P F$ over the canopy. However, when simulated for a commercial greenhouse with $800 \mathrm{~m}^{2}$, HPS lighting was shown to be $44 \%$ energy-saving than LED lighting (Pinho et al., 2012).

Plant growth rate per fixture's electric power consumption is highly correlated to the fixture's $P P F$ electrical efficiency $\left(\mu \mathrm{mol} \cdot \mathrm{s}^{-1} \cdot \mathrm{W}^{-1}\right.$ or $\left.\mu \mathrm{mol} \cdot \mathrm{J}^{-1}\right)$. More $P P F$ per watt $(\mathrm{W})$ often translates to greater growth rate per $\mathrm{kWh}$. If a LED fixture produces greater growth rate than a HPS fixture and both have similar PPF efficiency (LED: 0.84 to $2.3 \mu \mathrm{mol} \cdot \mathrm{J}^{-1}$, HPS: 0.93 to 1.85 $\left.\mu \mathrm{mol} \cdot \mathrm{J}^{-1}\right)$, two explanations are possible: 1) plant growth rate is much more enhanced by spectral optimization under the LEDs; and 2 ) the experimental design causes a disproportionate amount of supplemental $P P F$ of the HPS fixture to fall outside the growing area as a result of a higher fixture density and consequently higher energy consumption than supplemental LED fixtures. In the latter case, interpretation of energy consumption should be carefully done because it presents misleading information and is biased toward LEDs.

To our knowledge, no literature is available on the comparison of HPS to LED supplemental lighting for the production of 
greenhouse vegetable transplants. The objective of this study is to compare supplemental LED lighting with supplemental HPS lighting in terms of plant growth and development as well as the energy consumption of the fixtures. We have selected greenhouse cucumber transplants as the model crop because cucumber is the second most produced vegetable in hydroponic greenhouses in the United States (Nanfelt, 2011). In addition, cucumber is known to be sensitive to $P P F$ and light quality variations (Hernández and Kubota, 2014a, 2014b; Trouwborst et al., 2010a). Furthermore, cucumber transplants are commonly grown under HPS supplemental lighting in North America during the fall and winter months when solar DLI is the limiting factor for production.

\section{Materials and Methods}

Plant material and growing conditions. Cucumber (cv. Cumlaude) seeds (Rijk Zwaan, Bergschenhoek, The Netherlands) were germinated in rockwool plugs (plug size: $2.5 \mathrm{~cm}$ long $\times 2.5 \mathrm{~cm}$ wide $\times 4.0 \mathrm{~cm}$ high) (Grodan, Delta, Canada) at $28^{\circ} \mathrm{C}$ in the darkness for $24 \mathrm{~h}$. After radicle emergence, plugs were transferred to rockwool cubes (cube size: $10 \mathrm{~cm}$ long $\times 9.5 \mathrm{~cm}$ wide $\times$ $6.5 \mathrm{~cm}$ high) (Grodan) and moved to a greenhouse located in Tucson AZ. The greenhouse floor area was $108 \mathrm{~m}^{2}$ with $2.5-\mathrm{m}$ gutter height and $4.3-\mathrm{m}$ peak height and covered with double-layer acrylic glazing, oriented north to south, and equipped with a pad-andfan cooling system and a natural gas forced hot-air heating system. When cotyledons were expanded, uniform seedlings were selected and subjected to the supplemental lighting treatments. The plants were subirrigated as needed with nutrient solution containing (mg. $\mathrm{L}^{-1}$ ) 90 nitrogen, 47 phosphorus, 144 potassium, 160 calcium, 60 magnesium, 113 sulfur, 105 chlorine as well as micronutrients.

Solar DLIs were recorded everyday during the experiment using three quantum sensors (one per bench) (LI-190; LI-COR Inc., Lincoln, NE) placed at canopy height. Air temperature measured $60 \mathrm{~cm}$ above the canopy and canopy air temperature measured immediately below a fully expanded leaf at the top of canopy were recorded for each compartment using two fine-wire thermocouples (Type T, gauge 24; Omega Inc., Stamford, CT) (six thermocouples in the greenhouse). Atmospheric moisture was maintained by a misting system (Orbit Irrigation Products Inc., Bountiful, UT) installed under each bench (plants were not in contact with misting water). Relative humidity was measured using a humidity probe (HMP110; Vaisala Inc., Helsinki, Finland) installed in the middle of the experimental area. All sensors were connected to a CR-1000 data logger with a multiplexer (Campbell Scientific, Logan, UT) scanned every minute to record averages at 10 -min intervals.

Supplemental light treatments. In the north side of the greenhouse, three benches $\left(2.32 \mathrm{~m}^{2}\right)$ were positioned side by side and assigned for the three supplemental lighting treatments. These bench areas were separated by black plastic curtains to prevent light treatment contamination. The plastic curtains were placed so that air circulation was allowed under the three benches. Additional small curtains were positioned around the benches to achieve similar solar DLIs between the compartments. The three supplemental light treatments consisted of blue LEDs, red LEDs, and a HPS. Spectral photon flux distributions over the bench surface were measured on 40 locations in the growing area using a spectroradiometer (PAR-NIR; Apogee Instruments Inc., Logan, UT) and the treatment $P P F S$ were adjusted based on these data (Table 1). The phytochrome photostationary state (Pfr/Ptotal) was calculated for all three treatments following Sager et al. (1988) (Table 1). Individual experimental plants were systematically rotated daily inside the growing area to ensure even light exposure to all plants. Timers connected to the fixtures controlled the photoperiod, and kilowatt-hour sensors (Kill A Watt; P3 International Inc., New York, NY) monitored the electrical consumption of the individual fixtures.

Supplemental light fixtures. The LED fixtures (Orbital Technologies Inc., Madison, WI) used in the study were $131 \mathrm{~cm}$ long and $2 \mathrm{~cm}$ wide and mounted with 24 red [peak wavelength $633 \mathrm{~nm}$, full width at half maximum (FWHM): $16 \mathrm{~nm}$ ] or 24 blue (peak wavelength 443 nm, FWHM: 19 nm) LEDs. Each fixture had a 4.8-W cooling fan to lower LED operational temperature. A LED unit consisted of eight fixtures connected to a controller capable of varying the input amperage to set the required $P P F$ (Orbital Technologies Inc.). The LED unit was mounted horizontally $0.33 \mathrm{~m}$ above the bench with a $0.25-\mathrm{m}$ space between fixtures. The distance between the plants and the LED unit was maintained. A 600-W HPS fixture (P.L. Light Systems Inc., Beamsville, Ontario, Canada) with a deep reflector (P.L. Light Systems Inc.) was installed $1.65 \mathrm{~m}$ above the bench. Both the LED units and the HPS fixture irradiated an experimental bench area of $1.8 \mathrm{~m}^{2}$ with a fixture power density of $92.3,89.9$, and $364.4 \mathrm{~W} \cdot \mathrm{m}^{-2}$ for the blue LED, red LED, and HPS treatments, respectively. However, a significant portion of photons emitted by HPS fell outside of the bench area. This was taken into consideration when we compared the electrical power consumption.

Evaluation of electrical power consumption and growing efficiencies. In this study, the electrical power consumption of the three lighting systems was compared by extrapolating the experimental results to what can be expected for a commercial-scale greenhouse because a disproportional amount of radiation of the HPS fell outside the growing area in our experimental condition. A greenhouse area of 1 ha $\left(10,000 \mathrm{~m}^{2}\right)$ was used for the theoretical comparison. Two parameters $[A P C$ and $F G E$ in Eqs. (2) and (3)] were used to compare the three lighting systems in terms of

Table 1. Environmental parameters measured inside the greenhouse. ${ }^{z}$

\begin{tabular}{|c|c|c|c|c|c|}
\hline Measurement & Units & Blue LED & High-pressure sodium & Red LED & Specification \\
\hline$\overline{\text { Solar DLI }}$ & $\mathrm{mol} \cdot \mathrm{m}^{-2} \cdot \mathrm{d}^{-1}$ & $6.2 \pm 0.71$ & $6.3 \pm 1.13$ & $6.4 \pm 0.74$ & One location per treatment at canopy height \\
\hline Supplemental radiation & $\mu \mathrm{mol} \cdot \mathrm{m}^{-2} \cdot \mathrm{s}^{-1}$ & $55.7 \pm 3.1$ & $57.4 \pm 3.2$ & $57.3 \pm 3.0$ & $\begin{array}{l}\text { Measured at the beginning and end of } \\
\text { each repetition }\end{array}$ \\
\hline $\begin{array}{l}\text { Pf/Ptotal of } \\
\text { supplemental lighting }\end{array}$ & & 0.471 & 0.852 & 0.895 & $\begin{array}{l}\text { Measured at the beginning and end of } \\
\text { each repetition }\end{array}$ \\
\hline Greenhouse air temperature & ${ }^{\circ} \mathrm{C}$ & $\begin{array}{l}\text { Day: } 25.3 \pm 1.0 \\
\text { Night: } 15.9 \pm 1.1\end{array}$ & $\begin{array}{l}\text { Day: } 25.3 \pm 1.0 \\
\text { Night: } 16.6 \pm 1.2\end{array}$ & $\begin{array}{l}\text { Day: } 25.2 \pm 0.8 \\
\text { Night: } 16.1 \pm 1.2\end{array}$ & $\begin{array}{l}\text { One location, } 60 \mathrm{~cm} \text { above canopy for } \\
\text { each treatment }\end{array}$ \\
\hline Canopy air temperature & ${ }^{\circ} \mathrm{C}$ & $\begin{array}{l}\text { Day: } 23.5 \pm 0.5 \\
\text { Night: } 15.5 \pm 1.2\end{array}$ & $\begin{array}{l}\text { Day: } 24.0 \pm 0.6 \\
\text { Night: } 16.0 \pm 1.2\end{array}$ & $\begin{array}{l}\text { Day: } 23.3 \pm 0.6 \\
\text { Night: } 15.5 \pm 1.2\end{array}$ & $\begin{array}{l}\text { One location inside canopy for } \\
\text { each treatment }\end{array}$ \\
\hline Photoperiod & Hours & & $18(0200 \mathrm{HR}$ to $2000 \mathrm{HR})$ & & Solar ${ }^{\mathrm{w}}$ plus supplemental light \\
\hline Vapor pressure deficit & $\begin{array}{l}\mathrm{kPa} \\
\mathrm{kPa}\end{array}$ & & $\begin{array}{l}\text { Day: } 1.50 \pm 0.2 \\
\text { Night: } 0.74 \pm 0.1\end{array}$ & & One location, canopy height \\
\hline Atmospheric $\mathrm{CO}_{2}$ & $\mu \mathrm{mol} \cdot \mathrm{mol}^{-1}$ & & Ambient & & Natural ventilation \\
\hline Nutrient solution $\mathrm{pH}$ & & & $5.82 \pm 0.2$ & & Measured each fertigation \\
\hline Nutrient solution & $\mathrm{dS} \cdot \mathrm{m}^{-1}$ & & $2.10 \pm 0.09$ & & Measured each fertigation \\
\hline
\end{tabular}

${ }^{\mathrm{z}}$ Average and SDs of the two repetitions: 1) 22 Dec. 2012 to 28 Jan. 2013; and 2) 21 Apr. 2013 to 17 May 2013.

${ }^{y}$ Daily light integral.

${ }^{x}$ Phytochrome photostationary state (Pfr/Ptotal) was calculated for all three treatments following Sager et al. (1988)

${ }^{w}$ Sunset was at 1738 and 1909 HR for the replicated experiments.

LED $=$ light-emitting diode. 
fixture electrical consumption and growing efficiencies.

According to the method described by Aldrich and Bartock (1994), with some unit modification, the number of fixtures needed in a greenhouse $(N)$ can be expressed as:

$$
N=\frac{P P F \times A}{E P}
$$

where $P P F$ is the light intensity desired to add by the supplemental lighting (57 $\mu \mathrm{mol} \cdot \mathrm{m}^{-2} \cdot \mathrm{s}^{-1}$ in our experiment). $A$ is the target growing area $\left(10,000 \mathrm{~m}^{2}\right) . E P$ is the fixture-specific effective emission of photon $\left(\mu \mathrm{mol} \cdot \mathrm{s}^{-1}\right) . E P$ is calculated by multiplying the total photon emission rate of the fixture $\left(\mu \mathrm{mol} \cdot \mathrm{s}^{-1}\right)$ by its utilization factor (value that incorporates a fixture's beam distribution, reflector design, and geometries) and its maintenance factor (the decrease in fixture photon emissions over time). In this study, $E P$ for HPS and LED lighting was estimated as $81 \%$ and $85 \%$, respectively, of the photon emission rate of each fixture (Table 4).

Areal electric power consumption $(A P C)$ $\left(\mathrm{kW} \cdot \mathrm{m}^{-2}\right)$ by supplemental lighting was estimated in the following equation:

$$
A P C=\frac{N \times W F}{A}
$$

where $W F$ is the wattage required to power one fixture $(\mathrm{kW})$ (the power consumption by the cooling fans was not included in the calculation).

Finally, fixture growing efficiency $(F G E)$ expressed as grams of dry mass per $\mathrm{kWh}$ of energy consumption $\left(\mathrm{g} \cdot \mathrm{kWh}^{-1}\right)$ was calculated as follows:

$$
F G E=\frac{D M}{A P C \times T H}
$$

where $F G E$ is the fixture growing efficiency, $D M$ is the plant dry mass production per unit area $\left(\mathrm{g} \cdot \mathrm{m}^{-2}\right)$, and $T H$ is the total number of hours of supplemental lighting in the experiment ( $576 \mathrm{~h}$ in our experiment). Ideally, DM should account for the increase in DM associated with the supplemental lighting, but in this study, the total DM of plants collected at the end of experiment was used.

Plant measurements and experimental design. Twenty plants were sampled during the experiment when plants were at the second true-leaf stage (seedlings: 18 or $26 \mathrm{~d}$ after sowing) and when plants were at the seventh to eighth true-leaf stage (26 or $37 \mathrm{~d}$ after sowing). The number of growing days varied between the two repetitions as a result of seasonal environmental conditions. Plant height, hypocotyl length, and epicotyl length were measured using a ruler. Stem diameter was measured $1 \mathrm{~cm}$ below the cotyledons using a digital caliper. Plant shoots were cut at the substrate surface line, and the shoot fresh weight was recorded. Number of leaves greater than $1 \mathrm{~cm}$ in length was counted and recorded. Counted leaves and cotyledons were then scanned and leaf area per plant was calculated using the leaf area analysis software LIA 32 (K. Yamamoto, Nagoya, Japan). Chlorophyll concentration was quantified based on Moran and Porath (1980) for two $56.6-\mathrm{mm}^{2}$ leaf disks cut from each leaf plant. Plant shoots were individually packed in paper envelopes and placed into a drying oven at $80{ }^{\circ} \mathrm{C}$ for at least $48 \mathrm{~h}$ to obtain the shoot DM. Stomatal conductance and leaf net photosynthetic rate $(N P R)$ were measured with a portable photosynthesis system (CIRAS-2; PP System, Amesbury, MA) with a $1000 \mu \mathrm{mol} \cdot \mathrm{m}^{-2} \cdot \mathrm{s}^{-1} P P F$ (halogen lamp) under greenhouse temperature of $25 \pm 1{ }^{\circ} \mathrm{C}$ and ambient $\mathrm{CO}_{2}$ concentration.

The experiment was conducted twice: 1) 22 Dec. 2012 to 28 Jan. 2013; and 2) 21 Apr. 2013 to 17 May 2013. Each repetition had 40 cucumber plants (experimental units) per treatment for a total of 120 plants. Experimental plants were protected from edge effects by one row of 30 "border" plants. Analysis of variance $(P=0.05)$ was performed to identify treatment effect considering each plant as an experimental unit $(\mathrm{n}=40)$ repeated twice. Mean separations were analyzed using Tukey-Kramer honestly significant difference $(P=0.05)$. Analysis of variance confirmed that there were no significant interactions between the treatment and replication in time. The statistical analysis was performed using JMP software (SAS Institute, Cary, NC). No major differences were found between the seedling stage and the transplant stage; therefore, only the transplant stage results are presented.

\section{Results and Discussions}

Environmental conditions. Environmental conditions inside the greenhouse are shown in Table 1 . The average solar DLI was not significantly different among the three treatments. Air temperature above the plant canopy was maintained the same under all the treatments to minimize temperature effects on plant growth and morphology. Canopy air temperature measured was between 0.5 and $0.7{ }^{\circ} \mathrm{C}$ higher in the HPS treatment presumably as a result of the infrared radiation from the HPS fixture.

Effects of supplemental light on physiological responses of cucumber transplants. Shoot DM was $28 \%$ greater in the HPS treatment than that in the LED treatments and shoot fresh weight was $28 \%$ to $32 \%$ greater in the HPS treatment than that in the LED treatments (Table 2). Leaf number was $9 \%$ to $12 \%$ greater in the HPS treatment than that in the LED treatments (Table 2). These differences can be attributed to the higher canopy air temperature recorded in the HPS treatment caused by the higher infrared radiation emitted by the fixture. The actual leaf temperature (not measured) is expected to be higher than the measured canopy air temperature under the HPS fixture. Plant growth rate responds linearly to temperature increase (Adams, 2001; Lieth and Pasian, 1990). In the present experiment, the 0.5 to $0.7^{\circ} \mathrm{C}$ higher leaf temperature throughout the entire experiment could have caused the $28 \%$ increase in growth. Similar trends are reported by other research groups (Bergstrand and Schussler, 2013; Dueck et al., 2012; Islam et al., 2012). For example, in chrysanthemum, Bergstrand and Schussler (2013) recorded a 0.9 to $1.2{ }^{\circ} \mathrm{C}$ higher temperature and $17 \%$ greater DM in the supplemental HPS treatment compared with that in the supplemental red:blue LED treatment. Similarly, for poinsettias, Islam et al. (2012) showed $1.5{ }^{\circ} \mathrm{C}$ higher leaf temperature and $35 \%$ to $43 \%$ greater DM in the HPS supplemental light treatment than in the supplemental LED (20B:80R) treatment.

The difference in photosynthetically active radiation $(P A R)$ spectral composition between the treatments could have also influenced the increase in growth rate. The HPS spectrum applied in the present experiment was composed of $4.8 \%$ blue ( 400 to $500 \mathrm{~nm}$ ), $51 \%$ green $(500$ to $600 \mathrm{~nm})$, and $44 \%$ red (600 to $700 \mathrm{~nm}$ ) (photon flux over PAR) vs. $100 \%$ red and $100 \%$ blue for the LED light treatments. Supplemental lighting was turned on from $0200 \mathrm{HR}$ to $2000 \mathrm{HR}$ during which the first several hours ( 0200 HR to dawn) was the sole source of lighting and the following hours between dawn and dusk (10.3 to $13.5 \mathrm{~h}$ ) as supplemental lighting to the sunlight with the final 0.8 to $2.4 \mathrm{~h}$ (dusk to $2000 \mathrm{HR}$ ) as the sole source lighting. The solar plus electrical lighting spectrum generally vary depending on time of day, weather, day conditions, sky conditions, and growing season. In this study, the light quality for the solar plus electrical lighting was evaluated under a clear day

\begin{tabular}{|c|c|c|c|c|c|c|c|}
\hline Light treatment & $\begin{array}{c}\text { Plant stage } \\
\text { (days) }\end{array}$ & $\begin{array}{c}\text { Shoot dry } \\
\text { mass }(\mathrm{g})\end{array}$ & $\begin{array}{c}\text { Shoot fresh } \\
\text { wt }(\mathrm{g})\end{array}$ & Leaf number & Chlorophyll $^{\mathrm{z}}\left(\mathrm{g} \cdot \mathrm{m}^{-2}\right)$ & $\mathrm{NPR}^{\mathrm{y}}\left(\mu \mathrm{mol} \cdot \mathrm{m}^{-2} \cdot \mathrm{s}^{-1}\right)$ & $g_{\mathrm{S}}^{\mathrm{y}}\left(\mathrm{mmol} \cdot \mathrm{m}^{-2} \cdot \mathrm{s}^{-1}\right)$ \\
\hline$\overline{\text { Blue-LED }}$ & $26-37$ & $3.04 \pm 0.422 \mathrm{~b}^{\mathrm{x}}$ & $35.5 \pm 4.48 \mathrm{~b}$ & $7.4 \pm 0.587 \mathrm{~b}$ & $0.396 \pm 0.040 \mathrm{a}$ & $17.5 \pm 4.38 \mathrm{a}$ & $947 \pm 558 \mathrm{a}$ \\
\hline Red-LED & $26-37$ & $3.03 \pm 0.531 b$ & $34.5 \pm 6.37 \mathrm{~b}$ & $7.6 \pm 0.598 b$ & $0.375 \pm 0.038 b$ & $15.5 \pm 4.21 \mathrm{ab}$ & $721 \pm 320 b$ \\
\hline HPS & $26-37$ & $3.89 \pm 0.234 \mathrm{a}$ & $45.4 \pm 2.77 \mathrm{a}$ & $8.3 \pm 0.657 \mathrm{a}$ & $0.395 \pm 0.041 \mathrm{ab}$ & $13.1 \pm 3.58 \mathrm{~b}$ & $682 \pm 392 b$ \\
\hline
\end{tabular}
(9 Jan. 2013 and 14 May 2013) around solar

Table 2. Effects of supplemental HPS and LED lighting on plant growth and chlorophyll concentration of cucumber seedlings (mean \pm SD).

zTotal chlorophyll (a and b) per plant leaf area.

${ }^{y}$ Net photosynthetic rate (rate of $\mathrm{CO}_{2}$ exchange) and $g_{\mathrm{S}}$ measured for fully expanded leaves.

${ }^{x}$ Means followed by different lower or upper case letters are significantly different at $P \leq 0.05$.

$g_{\mathrm{S}}=$ stomatal conductance; HPS = high-pressure sodium; LED = light-emitting diode. 
noon, showing that blue, green, and red PF percentages of the treatments were $55 \%$, $21 \%$, and $24 \%$ for the supplemental blue LED treatment; $18 \%, 21 \%$, and $61 \%$ for the red LED treatment; and $20 \%, 40 \%$, and $40 \%$ for the HPS treatment, respectively (data not shown). The relative quantum efficiency (RQE) of blue, green, and red wavelengths for cucumber leaf were reportedly 0.646 , 0.840 , and 0.846 , respectively [from McCree (1972)]. Using wavelength-specific RQE and the spectral composition of the different light treatments throughout the photoperiod, it is possible to estimate the percent difference in yield photon flux (YPF) of each treatment. The YPF of the HPS treatment was $16 \%$ greater than that in the blue LED treatment and $1 \%$ lower than that in the red LED treatment. Spectral composition could have contributed to the greater growth rate of plants under HPS compared with those under blue LED treatment, but it does not explain the greater growth rate of plants under HPS compared with those under the red LED treatment.

Hernández and Kubota (2014a) recently examined different red-to-blue PF ratios of supplemental lighting using LEDs and demonstrated that cucumber growth rate decreased with the increase of blue PF under low solar DLI conditions $(5.2 \pm 1.2$ $\left.\mathrm{mol} \cdot \mathrm{m}^{-2} \cdot \mathrm{d}^{-1}\right)$. The reduction in growth rate was attributed to the reduction of leaf area caused by the increase of blue PF. In the present study, also conducted under low DLI conditions $\left(6.2 \pm 0.7 \mathrm{~mol} \cdot \mathrm{m}^{-2} \cdot \mathrm{d}^{-1}\right)$, it was expected to see a greater growth rate under the red LED treatment compared with the blue LED treatment. However, no differences in shoot DM, shoot fresh weight, and leaf number were found between the plants in the blue and red LED supplemental lighting treatments (Table 2). A key difference between the study conducted by Hernández and Kubota (2014a) and the present study is that the present study had a $100 \%$ blue treatment, whereas Hernández and Kubota (2014a) did not. This may have caused the differences in the results.

Total chlorophyll per leaf area was $6 \%$ greater in plants grown under the blue LED treatment compared with those in the red LED treatment and no significant different from those in the HPS treatment (Table 2). Chlorophyll biosynthesis has been reported to be associated with blue light. For example, Tripathy and Brown (1995) showed that blue light $\left(30 \mu \mathrm{mol} \cdot \mathrm{m}^{-2} \cdot \mathrm{s}^{-1}\right)$ restored chlorophyll synthesis on wheat seedlings germinated under red light alone $\left(500 \mu \mathrm{mol} \cdot \mathrm{m}^{-2} \cdot \mathrm{s}^{-1}\right)$. Oh-Hama and Hase (1981) demonstrated that blue light was critical to initiate chlorophyll biosynthesis in algae. In addition, chlorophyll concentration has been reported to increase with the increase of blue photon flux in algae (Jeffrey, 1980; Jeffrey and Vesk, 1981; Vesk and Jeffrey, 1977). Also, Hogewoning et al. (2010b) showed an increase in chlorophyll concentration with the increase of blue PF in cucumber seedlings grown under electrical light. More recently, Hernández and Kubota (2014a) tested different red and blue photon flux ratios of supplemental lightning $\left(55 \mu \mathrm{mol} \cdot \mathrm{m}^{-2} \cdot \mathrm{s}^{-1}\right)$ in greenhouse conditions and showed an increase in chlorophyll concentration with the increase of blue PF under low solar DLI conditions $\left(5.2 \mathrm{~mol} \cdot \mathrm{m}^{-2} \cdot \mathrm{d}^{-1}\right)$. In the present study, the blue PF percentages over $P P F$ were $\approx 55 \%, 18 \%$, and $20 \%$ for the blue LED, HPS, and red LED treatments, respectively, during the solar plus electrical lighting period (dawn to $2000 \mathrm{HR}$, measured at around solar noon) and $100 \%, 5 \%$, and $0 \%$ for the blue LED, HPS, and red LED treatments, respectively, during the electrical lighting period (0200 HR to dawn). Similar to Hernández and Kubota (2014a), in the present study, the greater the percentage of blue $\mathrm{PF}$, the greater the chlorophyll per leaf area under supplemental lighting conditions. It is plausible that plants under the blue LED treatment had greater capability to biosynthesize chlorophyll than plants under the red LED treatment.

Effects of supplemental light on net photosynthetic rate and stomatal conductance of cucumber transplants. Leaf NPR in the blue LED treatment was $34 \%$ greater than in the HPS treatment (Table 2). Leaf NPR in the blue -LED treatment was not significantly different from that in the red LED treatment (Table 2). Stomatal conductance was $31 \%$ and $39 \%$ greater in the blue LED treatment than in the red LED and HPS treatments, respectively (Table 2). Hogewoning et al. (2010b) showed no difference on NPR between plants grown under different percentages of blue $\mathrm{PF}$ $(7 \%, 15 \%, 22 \%, 50 \%)$ under low PPF (less than $\left.500 \mu \mathrm{mol} \cdot \mathrm{m}^{-2} \cdot \mathrm{s}^{-1}\right)$; however, at nearsaturating $P P F$ (500 to $2000 \mu \mathrm{mol} \cdot \mathrm{m}^{-2} \cdot \mathrm{s}^{-1}$ ), NPR increased with the increase of blue PF. The increase of NPR at the near saturating $P P F$ was attributed in part to the increase of $g_{\mathrm{S}}$ at near-saturating $P P F$ caused by the increase of blue PF. In the present study, similar to NPR responses, $g_{\mathrm{S}}$ measured at nearsaturating $P P F$ provided by the white light source was $39 \%$ and $31 \%$ greater in the blue LED treatment than in the HPS and red LED treatments, respectively (Table 2). Hogewoning et al. (2010b) showed a greater $g_{\mathrm{S}}$ in treatments with higher percent blue PF in cucumbers and the difference was more evident under higher PPF. Hogewoning et al. (2010b) attributed the increase in $g_{\mathrm{S}}$ in part to the increase in stomatal density in the adaxial leaf surface. Also, Savvides et al. (2012), in cucumbers, showed greater $g_{\mathrm{S}}$, stomatal density, pore aperture, and pore area per leaf area in the treatments with blue light (30B:70R, $100 \mathrm{~B})$ than in the treatment with only red light. In the present study, it is plausible that cucumbers plants under the blue LED treatment developed higher stomata density and size than in the red and HPS treatments (not measured), which could explain the higher leaf NPR and $g_{\mathrm{S}}$ at near-saturating $P P F(1000$ $\left.\mu \mathrm{mol} \cdot \mathrm{m}^{-2} \cdot \mathrm{s}^{-1}\right)$. However, because plants were grown under light limiting conditions (daytime maximum PPF: $453 \pm 109$ and $745 \pm$ 124 for replications 1 and 2, respectively), the greater photosynthetic capacity of the blue LED treatment under high $P P F$ did not reflect in a greater plant growth rate under the low growing $P P F$ of this study.

Effects of supplemental lighting on cucumber transplant morphology. Cucumber hypocotyl length was $46 \%$ and $61 \%$ greater in the blue LED and HPS treatments, respectively, than in the red LED treatment (Table 3; Fig. 1). Plant epicotyl length was 36 and $50 \%$ greater in the HPS treatment than in the blue LED and red LED treatments, respectively (Table 3 ). Stem diameter was $7 \%$ to $9 \%$ greater in the red LED treatment than in the HPS and blue LED treatments, respectively (Table 3 ). In the present study, plant height was greater in the HPS treatment followed by those in the blue LED treatment and red LED treatment (Table 3). The greater plant height in the HPS treatment compared with that in the blue LED treatment was mainly caused by the higher epicotyl length in the HPS. In contrast, the greater plant height in the HPS treatment compared with that in the red LED treatment is the result of the combination of greater epicotyl length and hypocotyl length of plants under the HPS treatment.

It has been reported that higher percentages of green/yellow light (500 to $600 \mathrm{~nm})$ caused stem elongation in plants (Mortensen and Strømme, 1987; Spaargaren, 2001). In this experiment, during the solar plus electrical lighting hours, the percentages of green/ yellow PF (measured at solar noon under a clear sky) were $40 \%$ in the HPS treatment compared with $22 \%$ in the LED treatments. Similarly, during the electrical lighting period (0200 HR to dawn), the percentages of green/ yellow PF were $51 \%$ for the HPS treatment and $0 \%$ for the LED treatments. Therefore, cucumber plants under the HPS treatment were exposed to higher percentages of green/yellow light during the entire experiment and this may have contributed to the higher plant height. Higher growing temperatures are also known

Table 3. Effects of supplemental HPS and LED lighting on morphological parameters of cucumber seedlings (mean \pm SD).

\begin{tabular}{lcccccc}
\hline Light treatment & Plant stage (days) & Plant ht $(\mathrm{cm})$ & Hypocotyl length $(\mathrm{cm})$ & Epicotyl length $(\mathrm{cm})$ & Stem diam $(\mathrm{mm})$ & Leaf area per plant $\left(\mathrm{m}^{2}\right)$ \\
\hline Blue LED & $26-37$ & $18.5 \pm 2.02 \mathrm{~b}^{2}$ & $5.80 \pm 0.75 \mathrm{a}$ & $12.5 \pm 2.15 \mathrm{~b}$ & $7.50 \pm 0.64 \mathrm{~b}$ & $0.081 \pm 0.011 \mathrm{~b}$ \\
Red LED & $26-37$ & $15.4 \pm 2.17 \mathrm{c}$ & $3.97 \pm 0.57 \mathrm{~b}$ & $11.3 \pm 1.63 \mathrm{~b}$ & $8.19 \pm 0.52 \mathrm{a}$ & $0.089 \pm 0.016 \mathrm{~b}$ \\
HPS & $26-37$ & $23.4 \pm 3.07 \mathrm{a}$ & $6.41 \pm 1.15 \mathrm{a}$ & $17.0 \pm 2.46 \mathrm{a}$ & $7.67 \pm 0.88 \mathrm{~b}$ & $0.102 \pm 0.026 \mathrm{a}$ \\
\hline
\end{tabular}

${ }^{2}$ Means followed by different lower or upper case letters are significantly different at $P \leq 0.05$.

HPS $=$ high-pressure sodium; LED $=$ light-emitting diode. 
to increase stem length. For example, Gray et al. (1998) reported that Arabidopsis thaliana seedlings grown at $29{ }^{\circ} \mathrm{C}$ temperature showed an $89 \%$ increase in hypocotyl elongation compared with seedlings grown at $20{ }^{\circ} \mathrm{C}$. In our experiment, the air temperature measured at the canopy was 0.5 to $0.7{ }^{\circ} \mathrm{C}$ higher in the HPS treatment compared with the LED treatments. However, in this experiment, we only measured air temperature in the canopy and not the leaf temperature. Therefore, the average leaf temperature differences between the treatments might have been higher than what was recorded in the canopy, which may have contributed to the higher stem extension in the HPS treatment. The greater plant height in the HPS treatment can also be attributed to the greater growth rate. In this experiment, plants under the HPS had $36 \%$ and $50 \%$ greater epicotyl length than in the blue LED and red LED treatment, respectively, and a $28 \%$ greater DM (greater growth rate). Greater stem length in plants under supplemental HPS treatment than plants under supplemental LED treatments has been documented before. For example, Islam et al. (2012) compared supplemental red:blue LEDs with HPS in their effects on plant height of poinsettias, and the research showed a $34 \%$ reduction of stem length when LEDs were used as supplemental light compared with the HPS. Currey and Lopez (2013) showed an $11 \%$ reduction in stem length in the $100 \%$ red LED supplemental light treatment compared with the plants under HPS supplemental light treatment in Petunia cuttings.
The lower plant height in the red LED treatment compared with that in the blue LED treatment is mainly attributed to the $46 \%$ reduction of hypocotyl length. The light quality at the end of day could have contributed to the difference of hypocotyl length between the two LED treatments. The addition of far-red (FR) light at the end of the day promotes hypocotyl elongation (Blom et al., 1996; Chia and Kubota, 2010; Decoteau et al., 1988; Kasperbauer and Peaslee, 1973). Research in different plant species showed that the response of stem length to the $\mathrm{Pfr} /$ Ptotal is linear; with the increase in $\mathrm{Pfr} /$ Ptotal, the stem extension rate decreases (Runkle and Heins, 2001; Smith, 1982). In the present study, the $\mathrm{Pfr} /$ Ptotal ratio is different between the red LED treatment (0.895) and the blue LED treatment $(0.471)$ (Table 1). This difference in Pfr/Ptotal in the present study may have contributed to the difference in hypocotyl length between the LED treatments.

Light quality during the electrical LED hours (0200 HR to dawn) can also have contributed to the difference of hypocotyl length between the two LED treatments. On a parallel experiment, we tested different red: blue photon flux ratios using LEDs as the sole source of light in cucumber and found that the hypocotyl length of the $0 \mathrm{R}: 100 \mathrm{~B}$ treatment was $53 \%$ greater than the hypocotyl length of the 100R:0B treatment (data not shown). Heo et al. (2002) also reported an increase of shoot length under pure blue light compared with red light in Salvia and marigold.

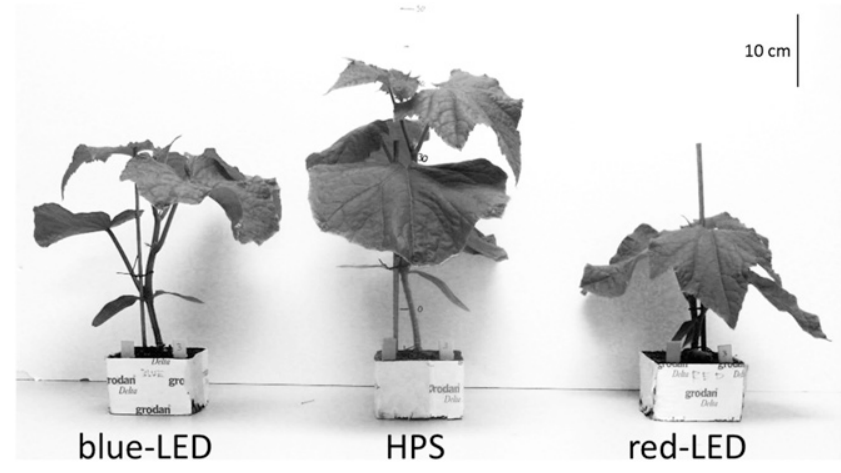

Fig. 1. Cucumber transplants grown for 26 to $37 \mathrm{~d}$ inside a greenhouse with an average of $6.3 \mathrm{~mol} \cdot \mathrm{m}^{-2} \cdot \mathrm{d}^{-1}$ solar daily light integral supplemented with $57 \mu \mathrm{mol} \cdot \mathrm{m}^{-2} \cdot \mathrm{s}^{-1}\left(3.7 \mathrm{~mol} \cdot \mathrm{m}^{-2} \cdot \mathrm{d}^{-1}\right)$ blue LED (left), HPS (center), and red LED (right) lighting. Notice that hypocotyl length was $46 \%$ to 61 greater in the blue LED and HPS treatment compared with the red LED treatment. LED = light-emitting diode; HPS = high-pressure sodium.

Plants under the red LED treatment had greater stem diameter and smaller hypocotyl length, and therefore they were more compact than the other two treatments (Table 3; Fig. 1). A compact plant is a desirable morphological characteristic for transplants. The use of chemical growth retardants to decrease plant height is under high regulation as a result of their potential health risk (Bergstrand and Schussler, 2013; Hendriks and Ueber, 1995; Lokke and Christensen, 2008). The use of supplemental lighting to increase the compactness of the transplants is a sound alternative to chemical growth regulators. Based on the results of this study, we recommend the use of red LED supplemental light to increase cucumber transplant compactness.

Leaf area was greater in the HPS treatment than in the LED treatments (Table 3 ). This can be attributed to the greater growth rate of the plants grown under the HPS treatment. Leaf area was between $15 \%$ and $26 \%$ higher in the HPS than in the red LED and blue LED treatments, respectively, and plant DM was $28 \%$ higher in the HPS than in the LED treatments. Leaf area in the red LED treatment was not significantly greater than in the blue LED treatment. Under sole-source light, the decrease of leaf area with the increase of blue PF has been reported in cucumber (Hogewoning et al., 2010a; Trouwborst et al., 2010b) and lettuce (Li and Kubota, 2009). More recently under supplemental LED lighting, cucumber seedling leaf area also decreased with the increase of blue PF under low solar DLI conditions $\left(5.2 \mathrm{~mol} \cdot \mathrm{m}^{-2} \cdot \mathrm{d}^{-1}\right)$ (Hernández and Kubota, 2014a). Leaf responses to higher percentages of blue PF (under the same $P P F)$ are similar to leaf responses to $P P F$ increase (Hogewoning et al., 2010b; Poorter et al., 2009, 2010). It appears that when irradiating plants with different ratios of red: blue PF, the increase of blue PF decreases leaf area, but when irradiating with pure blue, leaf area is not reduced. In the present study, the red:blue PF ratio was lower in the blue treatment (more blue PF) during the solar plus electrical lighting hours (dawn to dusk) potentially causing a small decrease in leaf area, but this may have been compensated by the electrical lighting hours $(0200$ HR to dawn) when cucumber plants were irradiated with pure blue PF.

Evaluation of fixture electrical consumption. High-pressure sodium lamps are the standard

Table 4. Estimation of areal power consumption and fixture growing efficiency. ${ }^{2}$

\begin{tabular}{lccccc}
\hline $\begin{array}{l}\text { Lamp type } \\
\text { and ballast }\end{array}$ & $\begin{array}{c}\text { Input } \\
\text { power }(\mathrm{kW})\end{array}$ & $\begin{array}{c}\text { Fixture } P P F \\
\text { efficiency } \\
\left(\mu \mathrm{mol} \cdot \mathrm{J}^{-1}\right)\end{array}$ & $\begin{array}{c}\text { Effective } \\
\text { photons } \\
\left(\mathrm{EP}, \mu \mathrm{mol} \cdot \mathrm{s}^{-1}\right)^{\mathrm{w}}\end{array}$ & $\begin{array}{c}\text { Number of } \\
\text { fixtures per hectare }\end{array}$ & $\begin{array}{c}\text { Areal power } \\
\text { consumption }\left(\mathrm{kW} \cdot \mathrm{m}^{-2}\right)\end{array}$ \\
Blue LEDs & 0.0427 & $1.9^{\mathrm{y}}$ & 69 & 8258 & 0.035 \\
600-W HPS & 0.656 & $1.64^{\mathrm{y}, \mathrm{x}}$ & 871 & 655 & 0.043 \\
Red LEDs & 0.0218 & $1.7^{\mathrm{y}}$ & 31 & 18124 & 0.039 \\
\hline
\end{tabular}

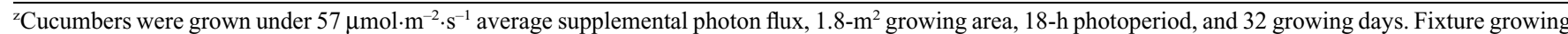
efficiency was calculated using the growing area shoot dry mass means and the total power consumption.

${ }^{y}$ Values provided by Nelson and Bugbee $(2014)$ for red LED $(655 \mathrm{~nm})$ and blue LED $(455 \mathrm{~nm})$.

${ }^{\mathrm{x}}$ Calculated by dividing the manufacturer specific photon emission rate $\left(1075 \mu \mathrm{mol} \cdot \mathrm{s}^{-1}\right)$ by the input power $656 \mathrm{~W}$.

${ }^{\mathrm{w}} \mathrm{EP}$ was considered as $81 \%$ and $85 \%$ of total photon emission of HPS and LEDs (see the text for more information).

$P P F=$ photosynthetic photon flux; LEDs $=$ light-emitting diodes; HPS $=$ high-pressure sodium. 
supplemental lighting technology used in greenhouses as a result of their relatively high efficiency (1.5 to $\left.1.89 \mu \mathrm{mol} \cdot \mathrm{J}^{-1}\right)$ and high effective flux (greater than $1000 \mu \mathrm{mol} \cdot \mathrm{s}^{-1}$ for fixtures over $600 \mathrm{~W}$ ). In commercial greenhouses, HPS fixtures are installed at considerable distance above the plant canopy and the overlapping light beams from multiple fixtures improve light uniformity and intensity (photon flux). It is challenging to do a fair energy consumption comparison between HPS and LEDs in a small-scale research area. For example, in this study, to achieve the same $P P F$ between LED and HPS treatments, LED fixtures were installed close to the plant canopy ( $0.33 \mathrm{~m}$ above the canopy) because they had a relatively low effective flux (37 to 87 $\mu \mathrm{mol} \cdot \mathrm{s}^{-1}$ ) and most of the radiation fell within the growing area $\left(1.8 \mathrm{~m}^{-2}\right)$. In contrast, the HPS was installed $1.65 \mathrm{~m}$ above the canopy and a disproportionate amount of radiation fell outside the target area. Under the present experimental conditions, HPS fixture density was 0.56 fixtures $/ \mathrm{m}^{2}$ and the APC was $364 \mathrm{~W} \cdot \mathrm{m}^{-2}(600-\mathrm{W}$ HPS electrical consumption including ballast: $656 \mathrm{~W})$. To achieve the same PPF $(57 \pm 3.1$ $\left.\mu \mathrm{mol} \cdot \mathrm{m}^{-2} \cdot \mathrm{s}^{-1}\right)$, in a commercial-scale greenhouse operation (i.e., 1-ha area), using Eqs. [1] and [2], the HPS fixture density and the APC would have been $0.05 \mathrm{~m}^{-2}$ and $42.9 \mathrm{~W} \cdot \mathrm{m}^{-2}$ $\left(0.043 \mathrm{~kW} \cdot \mathrm{m}^{-2}\right)$, respectively (Table 4$)$. The calculated APC is $\approx 10$ times smaller than the experimental APC and agreed with the APC of supplemental lighting in a commercial greenhouse in Canada (L. Benne, personal communication). The HPS treatment had $23 \%$ and $10 \%$ greater APC than the blue LED and red LED treatments, respectively (Table 4). However, the HPS treatment had $6 \%$ and $17 \%$ greater FGE than the blue LED and red LED treatments, respectively (Table 4). This is mainly attributed to the higher canopy temperature caused by the infrared radiation emitted by the HPS. However, the FGE in the present study was obtained based on the fixture PPF efficiency reported by Nelson and Bugbee (2014) for blue and red LEDs (1.9 and $\left.1.7 \mu \mathrm{mol} \cdot \mathrm{J}^{-1}\right)$ (Table 4). Currently, LED fixtures with higher $P P F$ efficiencies are available in the market. For example, a commercial LED fixture containing red and blue diodes for greenhouse applications is reported to have a fixture efficiency of $2.3 \mu \mathrm{mol} \cdot \mathrm{J}^{-1}$ (Philips, 2014). If these high-efficiency LEDs were used, a fixture growing efficiency of $4 \mathrm{~g} \cdot \mathrm{kWh}$ could be achieved, which is $14 \%$ greater than the value obtained under a HPS fixture in the present study.

\section{Conclusion}

Cucumber plants under supplemental HPS lighting had greater growth rate than plants under LED supplemental lighting. The greater growth rate under the HPS treatment was attributed to higher leaf temperatures caused by the infrared radiation produced by the fixture. Transplant morphology was more desirable under the red LED supplemental lighting because cucumber transplants were more compact. Leaf net photosynthetic rate and $g_{\mathrm{S}}$ were higher under the blue LED treatment. However, they did not translate into a higher growth rate. Compared with reported LED efficiencies (1.7 to 1.9 $\left.\mu \mathrm{mol} \cdot \mathrm{J}^{-1}\right)$, HPS $\left(1.6 \mu \mathrm{mol} \cdot \mathrm{J}^{-1}\right)$ had a higher fixture growing efficiency $\left(\mathrm{g} \cdot \mathrm{kWh}^{-1}\right)$ than the LED fixtures; however, this is expected to change because LED fixture efficiencies keep increasing. More research is needed to explain unique morphological vegetable plant responses caused by unique spectrums obtainable with LED technology. The responses to supplemental light quality of other economically important greenhouse crops needs to be investigated.

\section{Literature Cited}

Adams, S.R. 2001. Effect of temperature on the growth and development of tomato fruits. Ann. Bot. (Lond.) 88:869-877.

Aldrich, R.A. and J.W. Bartock. 1994. Greenhouse engineering, NRAES-Natural Resources, Agriculture, and Engineering Service, Ithaca, NY.

Bergstrand, K.J. and H.K. Schussler. 2013. Growth, development and photosynthesis of some horticultural plants as affected by different supplementary lighting technologies. European Journal of Horticultural Science 78:119-125.

Blom, T.J., M.J. Tsujita, and G.L. Robert. 1995. Far-red at end of day and reduced irradiance affect plant height of Easter and Asiatic hybrid lilies. HortScience 30:1009-1012.

Brown, C.S., A.C. Schuerger, and J.C. Sager. 1995. Growth and photomorphogenesis of pepper plants under red light-emitting diodes with supplemental blue or far-red lighting. J. Amer. Soc. Hort. Sci. 120:808-813.

Chia, P.L. and C. Kubota. 2010. End-of-day far-red light quality and dose requirements for tomato rootstock hypocotyl elongation. HortScience 45:1501-1506.

Currey, C.J. and R.G. Lopez. 2013. Cuttings of impatiens, pelargonium, and petunia propagated under light-emitting diodes and high-pressure sodium lamps have comparable growth, morphology, gas exchange, and post-transplant performance. HortScience 48:428-434.

Decoteau, D.R., M.J. Kasperbauer, D.D. Daniels, and P.G. Hunt. 1988. Plastic mulch color effects on reflected light and tomato growth. Sci. Hort. 34:169-175.

Dueck, T.A., J. Janse, B.A. Eveleens, F.L.K. Kempkes, and L.F.M. Marcelis. 2012. Growth of Tomatoes under hybrid LED and HPS lighting. International Symposium on Advanced Technologies and Management Towards Sustainable Greenhouse Ecosystems: Greensys 2011, 952. p. 335-342.

Goins, G.D., N.C. Yorio, M.M. Sanwo, and C.S. Brown. 1997. Photomorphogenesis, photosynthesis, and seed yield of wheat plants grown under red light-emitting diodes (LEDs) with and without supplemental blue light. J. Expt. Bot. 48:1407-1413.

Gomez, C., R.C. Morrow, C.M. Bourget, G.D. Massa, and C.A. Mitchell. 2013. Comparison of intracanopy light-emitting diode towers and overhead high-pressure sodium lamps for supplemental lighting of greenhouse-grown tomatoes. HortTechnology 23:93-98.

Gray, W.M., A. Ostin, G. Sandberg, C.P. Romano, and M. Estelle. 1998. High temperature promotes auxin-mediated hypocotyl elongation in Arabidopsis. Proc. Natl. Acad. Sci. USA 95:7197-7202.
Haitz, R. and J.Y. Tsao. 2011. Solid-state lighting: 'The case' 10 years after and future prospects. Physica Status Solidi (a) 208:17-29.

Hendriks, L. and E. Ueber. 1995. Alternative methods of regulating the elongation growth of ornamental plants: A current assessment. Acta Hort. 378:159-167.

Heo, J., C. Lee, D. Chakrabarty, and K. Paek. 2002. Growth responses of marigold and salvia bedding plants as affected by monochromic or mixture radiation provided by a light-emitting diode (LED). Plant Growth Regulat. 38:225-230.

Hernández, R. and C. Kubota. 2014a. Growth and morphological response of cucumber seedlings to supplemental red and blue photon flux ratios under varied solar daily light integrals. Sci. Hort. 173C:92-99.

Hernández, R. and C. Kubota. 2014b. LEDs supplemental lighting for vegetable transplant production: Spectral evaluation and comparisons with HID technology. Acta Hort. 1037:829-835.

Hogewoning, S.W., D. Peter, G. Trouwborst, W Van Leperen, and J. Harbinson. 2010a. An artificial solar spectrum substantially alters plant developmenr compared with usual climate room irradiance spectra. J. Expt. Bot. 61:1267-1276.

Hogewoning, S.W., G. Trouwborst, H. Maljaars, H. Poorter, W. Van Leperen, and J. Harbinson. 2010b. Blue light dose-response of leaf photosynthesis, morphology, and chemical composition of Cucumis sativus grown under different combinations of red and blue light. J. Expt. Bot. 61:3107-3117.

Islam, M.A., G. Kuwar, J.L. Clarke, D.R. Blystad, H.R. Gislerod, J.E. Olsen, and S. Torre. 2012. Artificial light from light emitting diodes (LEDs) with a high portion of blue light results in shorter poinsettias compared to high pressure sodium (HPS) lamps. Sci. Hort. 147:136-143.

Jeffrey, S.W. 1980. Responses to light in aquatic plants. In: Pirson, A. and M.H. Zimmermann (eds.). Encyclopedia of planta physiology. Springer-Verlag, Berlin, Germany.

Jeffrey, S.W. and M. Vesk. 1981. Blue-green light effects in marine microalgae: Enhanced thylakoid and chlorophyll synthesis, p. 435442. In: Akoyunoglou, G. (ed.). Photosynthesis VI-Photosynthesis and productivity. Balaban, Philadelphia, PA.

Kasperbauer, M.J. and D.E. Peaslee. 1973. Morphology and photosynthestic efficiency of tabacco leaves that received end-of-day red or far red light during development. Plant Physiol 52:440-442.

Kim, H.-H., R.M. Wheeler, J.C. Sager, N.C. Yorio, and G.D. Goins. 2005. Light-emiting diodes as an illumination source for plants: A review of research at Kennedy Space Center. Habitation (Elmsford) 10:71-78.

Li, Q. and C. Kubota. 2009. Effects of supplemental light quality on growth and phytochemicals of baby leaf lettuce. Environ. Expt. Bot. 67:5964.

Lieth, J.H. and C.C. Pasian. 1990. A model for net photosynthesis of rose leaves as a function of photosynthetically active radiation, leaf temperature, and leaf age. J. Amer. Soc. Hort. Sci. 115:486-491.

Lokke, S. and P. Christensen. 2008. The introduction of the precautionary principle in Danish environment policy: The case of plant growth retardants. J. Agr. Environ. Ethics 21:229-247.

Martineau, V., M. Lefsrud, M.T. Naznin, and D.A. Kopsell. 2012. Comparison of light-emitting diode and high-pressure sodium light 
treatments for hydroponics growth of Boston lettuce. HortScience 47:477-482.

Massa, G.D., H.-H. Kim, and R.M. Wheeler. 2008. Plant productivity in response to LED lighting. HortScience 43:1951-1956.

McCree, K.J. 1972. The action spectrum, absorpance and quantum yield of photosynthesis in crop plants. Agr. Meteorol. 9:191-216.

Moran, R. and D. Porath. 1980. Chlorophyll determination in intact tissues using N,Ndimethylformamide. Plant Physiol. 65:478-479.

Mortensen, L.M. and E. Strømme. 1987. Effects of light quality on some greenhouse crops. Sci. Hort. 33:27-36.

Nanfelt, M. 2011. Hydroponic crop farming. IBIS World Industry Report OD4012.

Nelson, J. and B. Bugbee. 2013. Supplemental greenhouse lighting: Return on investment for LED and HPS fixtures. Utah State University. 10 Jan. 2014. <http://cpl.usu.edu/htm/research/ by $=$ category $/$ category $=871 /$ start $=21>$.

Nelson, J.A. and B. Bugbee. 2014. Economic analysis of greenhouse lighting: Light emitting diodes vs high intensity discharge fixtures. PLoS ONE 9:e99010.

Oh-Hama, T. and E. Hase. 1981. Role of light in 5 -aminolevulinic acid formation in wild strain and mutant C-2A cells of Scenedesmus obliquus. Plant Cell Physiol. 22:747758 .
Philips. 2014. The new fast-track to growth: Philips GreenPower LED toplighting. (ed.). N.V. Philips, The Netherlands.

Philips-Electronics. 2012. Profitable growth Master GreenPower Plus 66 W EL \& 1000 W EL. ELECTRONICS, K. P. (ed.). N.V. Philips, The Netherlands.

Pinho, P., T. Hytonen, M. Rantanen, and $\mathrm{P}$. Elomaa. 2012. Dynamic control of supplemental lighting intensity in a greenhouse environment. Lighting Res. Tech. 0:1-10.

Poorter, H., Ü. Niinemets, L. Poorter, I.J. Wright, and R. Villar. 2009. Causes and consequences of variation in leaf mass per area (LMA): A meta-analysis. New Phytol. 182:565-588.

Poorter, H., Ü. Niinemets, A. Walter, F. Fiorani, and U. Schurr. 2010. A method to construct dose-response curves for a wide range of environmental factors and plant traits by means of a meta-analysis of phenotypic data. J. Expt. Bot. 61:2043-2055.

Runkle, E.S. and R.D. Heins. 2001. Specific functions of red, far red, and blue light in flowering and stem extension of long-day plants. J. Amer. Soc. Hort. Sci. 126:275-282.

Sager, J.C., W.O. Smith, J.L. Edwards, and K.L. Cyr. 1988. Photosynthetic efficiency and phytochrome photoequilibria determination using spectral data. Trans. ASAE 31:1882-1889.
Savvides, A., D. Fanourakis, and W. Van Ieperen. 2012. Co-ordination of hydraulic and stomatal conductances across light qualities in cucumber leaves. J. Expt. Bot. 63:1135-1143.

Smith, H. 1982. Light quality, photoperception and plant strategy. Ann. Rev. Plant Physiol. 33:481-518.

Spaargaren, I.J.J. 2001. Supplemental lighting for greenhouse crops. Hortilux Schreder, Moster, The Netherlands.

Tripathy, B.C. and C.S. Brown. 1995. Root-shoot interaction in the greening of wheat seedlings grown under red light. Plant Physiol. 107:407411.

Trouwborst, G., J. Oosterkamp, S.W. Hogewoning, J. Harbinson, and W. Van Ieperen. 2010a. The responses of light interception, photosynthesis and fruit yield of cucumber to LED-lighting within the canopy. Physiol. Plant. 138:289300 .

Trouwborst, G., J. Oosterkamp, S.W. Hogewoning, J. Harbinson, and W. Van Leperen. $2010 \mathrm{~b}$. The responses of light interception, photosynthesis and fruit yield of cucumber to LED-lighting within the canopy. Physiol. Plant. 138:289-300.

Vesk, M. and S.W. Jeffrey. 1977. Effect of bluegreen light on photosynthetic pigments and chloroplast structure in unicellular marine algae form six classes. J. Phycol. 13:280-288. 